JELTL (Journal of English Language Teaching and Linguistics) e-ISSN: 2502-6062, p-ISSN: 2503-1848

2019, Vol. 4(3)

www.jeltl.org

\title{
Vietnamese EFL Students' Habits of Using Dictionaries in Translation Practice in ESP Courses
}

\author{
Lien Thi My Tong \\ University of Languages and International Studies, Vietnam National University, Vietnam \\ tongthimylien85@gmail.com
}

\begin{abstract}
Doing translation tasks, especially in English-for-Specific-Purposes (ESP) courses, is probably demanding and challenging, which requires students' utilization of dictionaries and other tools. Thus, this study was conducted to investigate Vietnamese English-as-aForeign-Language (EFL) students' habits of dictionary consultation in ESP translation. The data were collected during a three-week period among 75 third-year EFL students from three classes at University of Languages and International Studies (ULIS), Vietnam National University (VNU) by a combination of quantitative and qualitative methods (i.e. survey questionnaires with a combination of close-ended and open-ended questions). The research highlighted the students' positive attitudes towards dictionary use together with a high level of its frequency in translating ESP texts, their definite preference for dictionary applications for mobile phones and bilingual dictionaries as well as their prioritized lookups such as equivalents, examples, equivalent usage, and word definitions. In addition, it revealed that the students were confident in their capability of exploiting the dictionaries in ESP translation and thus had little desire for teachers' assistance and guidance.
\end{abstract}

Keywords: dictionaries, ESP courses, translation, Vietnamese EFL students

\section{INTRODUCTION}

Apparently, due to the accelerated pace of globalization, there has been a growing demand for translation, which can handle language barriers as well as facilitate communication and interaction in numerous fields. This means that university graduates demonstrating a high level of competence in translation are probably employable in the 


\section{Lien Thi My Tong}

fiercely competitive labor market. Thus, it is advisable to consider translation a crucial skill to be acquired and sharpened at tertiary level (Avand, 2009).

As regards Vietnam's educational context, with the aim of assisting students in reaching more advantageous positions in their future career, University of Languages and International Studies (ULIS), Vietnam National University (VNU) has included translation in the curriculum of English-for-Specific-Purposes (ESP) courses designed for those majoring in English - Business Administration (EBA), English - Finance and Banking (EFB), and English - International Business (EIB). Nevertheless, it is an indisputable fact that translating texts, especially ESP ones, is demanding and challenging, which requires students to consult dictionaries and other tools in search for not only factual but also linguistic reference (Hartmann \& James, 2000). Consequently, research into the sub-area of English-as-a-Foreign-Language (EFL) students' use of different tools in ESP translation might yield valuable, relevant findings and hence make substantial contributions to the field of ESP and EFL teaching in Vietnam in general and at this site in particular.

Furthermore, in the second or foreign language acquisition process, dictionaries have been utilized extensively to enhance language skills since they could possibly "scaffold language learning both within and outside the classroom" (Jin \& Deifell, 2013), offering a large amount of useful information such as word definitions, usage, pronunciation, and so on. They are also regarded as an indispensible tool in translation. As Ramos (2005) claims, its effective use would be highly beneficial to translators. Specifically, enormous lexical knowledge gained from this source tends to facilitate their understanding of the original text and support them in producing a desirable target text (Zhang, 2010; Ramos, 2005; Mahmoud, 2017). It is, therefore, worth investigating the employment of dictionaries in doing translation tasks.

Meanwhile, research to date such as those by Kondal (2018), Boonmoh (2012), and Tananuraksakul (2015) has examined this matter thoroughly but primarily in the area of second or foreign language acquisition. In other words, investigations into this matter in translation were small in number. For example, Mahmoud (2017) attempted to identify whether EFL students should be permitted to consult dictionaries during translation tests and examinations; in the meantime, Małgorzata's investigation (2016) into learners' use of dictionaries and other resources in performing translation tasks highlighted their preference for online resources rather than traditional paper dictionaries, as opposed to an empirical study by Ramos (2005), indicating students' marked incapability of utilizing different types of dictionaries and considerable unfamiliarity with dictionary software and online dictionaries. Some other studies like the one by Liang \& Xu (2018) focused on only one specific type of dictionaries. Furthermore, all those few studies have not elaborated on dictionary consultation in translating ESP texts. Thus, a study on EFL students' utilization of this tool in doing ESP translation tasks would be highly appreciated.

The present research was undertaken to explore Vietnamese EFL students' habits of using dictionaries in translation practice in ESP courses. Particularly, it addressed the following research questions:

1. What is EFL students' attitude towards dictionary use in translation practice in ESP courses? 
2. How often do they consult dictionaries while translating ESP texts, and what types of dictionaries do they favor?

3. What do they seek when consulting dictionaries in their ESP translation practice?

4. Do they need teachers' instructions in dictionary use in translating ESP texts?

With its new population in a different education context, it was expected to generate reliable, useful findings to bridge the existing gaps in the literature concerning EFL learners' dictionary use in translation, especially in ESP courses.

\section{LITERATURE REVIEW}

Although countless research has been done on the theme of dictionary use for decades, this vast amount appears to mainly target the language acquisition process. For example, Kondal (2018) attempted to examine learners' consultation of this tool for general language learning purposes whereas Boonmoh (2012), Tananuraksakul (2015), and Laufer \& Hill (2000) discussed its role in boosting vocabulary or particular skills like writing.

Moreover, of all the sub-topics of dictionary employment in language acquisition, learners' habits have been under extensive investigation. To name but a few, Haill \& Nesi (2002) elaborated on international students' habits of consulting dictionaries for definitions of new words and highlighted their difficulties in selecting appropriate entries while Fan (2000) concluded that most students relied on bilingualized and bilingual dictionaries for their vocabulary acquisition.

Ahmad \& Haq (2010) also explored the habits of employing dictionaries but as a tool of information (for definitions or explanations of medical terms) among medical EFL students. Noticeably, the participants in this study did not demonstrate frequent use due to not being trained or motivated to do it.

Li's research (1998) was somehow close to the current research as it studied the use of dictionaries by Chinese learners of ESP. However, they utilized this tool for a range of purposes, namely translating/ reading texts and finding word usage or connotations. This investigation revealed their positive attitudes towards dictionary exploitation, their preference for bilingual or bilingualized dictionaries and electronic or online dictionaries, and their desire for teachers' instructions in using dictionaries.

Strikingly, few studies have been conducted to investigate the matter in translation. For instance, Mahmoud (2017) endeavored to determine whether this tool should be accessible among EFL students in translation tests and examinations. Additionally, Małgorzata (2016), who examined the use of dictionaries and other resources in handling translation tasks by a group of students of English Philology, found out that this population favored online resources rather than traditional paper dictionaries. By contrast, an empirical study was conducted with translation students by Ramos (2005), indicating the participants' noticeable incapability of making efficient use of different types of dictionaries and relative unfamiliarity with dictionary software and online dictionaries and consequently emphasizing constant needs for training in dictionary use. This somehow coincided with the case study by Law (2009) into the dictionary consultation pattern of EFL translation students, concluding that students encountered plenty of difficulties in consulting Chinese-English dictionaries and recommending teaching dictionary skills to students from the primary to tertiary levels. Some other studies focused on only one specific type of dictionaries. For example, Liang \& 
$\mathrm{Xu}$ (2018) solely examined EFL learners' use of a specific brand of dictionary software for computers in performing a translation task and indicated their tendency to look up equivalents and content words.

Overall, researchers have paid enormous attention to elaboration on students' habits of dictionary use in the acquisition of language skills rather than in translation. Meanwhile, those few in translation do not touch upon ESP courses. Thus, the current research aiming at examining students' consultation of dictionaries in translating ESP texts in an EFL educational setting could be a worthy, significant addition to the existing literature.

\section{RESEARCH METHODS}

Both quantitative and qualitative methods were employed to supplement each other as merely adopting a single approach involves a number of limitations (Nunan, 1992). The quantitative method is believed to provide objective, quantifiable and generalized data (Abbott \& Bordens, 1999) whilst the qualitative method is excellent at "yielding real, rich and deep data" (Brown \& Rodgers, 2002).

\subsection{Participants}

The participants were 75 third-year students from three classes, each of which majors in one of the following: EBA, EFB, and EIB at Faculty of English Language Teacher Education (FELTE) at ULIS, VNU. They started to take ESP courses in their third year, all of which include translation practice. Thus, this choice of the population could help to ensure research validity and credibility.

\subsection{Instruments}

The data were collected over three weeks by survey questionnaires, which are timeefficient with plenty of relevant information (Nunan, 1992). The questionnaire (see Appendix) contained 15 questions, most of which were close-ended (in the form of either a Likert scale or multiple choices) since these types of questions are supposed to be handy for the participants to answer as well as convenient for the researcher's later data collation and analysis (Mallick \& Vajendra, 1999). Not only was the option "others (please specify)" added to most of them but one open-ended question was also included so as to minimize any superficiality in the responses and enrich the collected data.

The first questionnaire version was piloted online with 10 randomly-chosen third-year students majoring in EBA at FELTE at ULIS, VNU. Subsequently, thorough revision was made to ensure its accuracy and conciseness before the questionnaires were distributed to 75 students directly in class so that the researcher could provide support if any confusion arose. A brief introduction about the study was given together with the researcher's careful oral instructions to lessen any misunderstanding and ambiguity.

\subsection{Data Analysis}

All the responses from 75 completed questionnaires were later counted and illustrated in pie charts and bar charts in order that the researcher could perform in-depth quantitative data analysis. As for some qualitative data collected from the questionnaires, they were 
classified, listed, put in tables or figures (if possible and necessary), and later utilized to supplement or further explain the statistical information. Finally, all the data were categorized into four primary areas corresponding to the four research questions.

\section{FINDINGS AND DISCUSSION}

\subsection{Students' attitudes towards using dictionaries in translation practice in ESP courses}

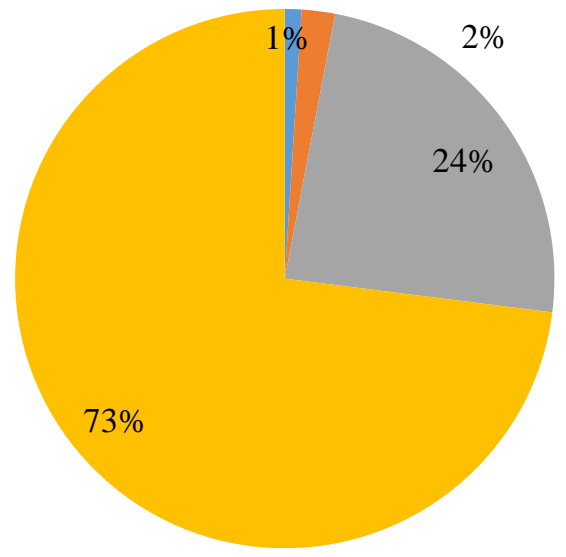

- Slightly beneficial

- Quite beneficial

$\square$ Very beneficial

Extremely beneficial

Figure 1: Students' attitudes towards using dictionaries in translating ESP texts

As can be seen from Figure 1, the respondents expressed favorable attitudes with nearly $100 \%$ agreeing that exploiting dictionaries would be beneficial to their translation process. Strikingly, nearly three fourths of them emphasized the importance of dictionaries by marking number 5 on the Likert scale (equal to extremely beneficial).

This finding closely coincided with what was identified by Li (1998). Amazingly, her research subjects were similar: a group of ESP learners, and they also demonstrated positive attitudes towards dictionary consultation. This could be easily understood as dictionaries always offer a tremendous amount of valuable information as explained by Zhang (2010), Ramos (2005), and Mahmoud (2017), of which students tend to be fully aware whatever educational contexts they are in.

\subsection{Frequency of students' dictionary consultation in translation practice in ESP courses and their preferences in types of dictionaries}

Figure 2 illustrates the frequency of dictionary use among the respondents while translating texts in ESP courses. Interestingly, almost all of them had a high level of frequency with even over two thirds stating that they always consulted dictionaries when doing a translation task. It is also remarkable to note that no one ticked 1 (equal to never) or 2 (equal to rarely) on the Likert scale. This is unsurprisingly consistent to their intense awareness of the importance of this tool in ESP translation practice (see 4.1). 


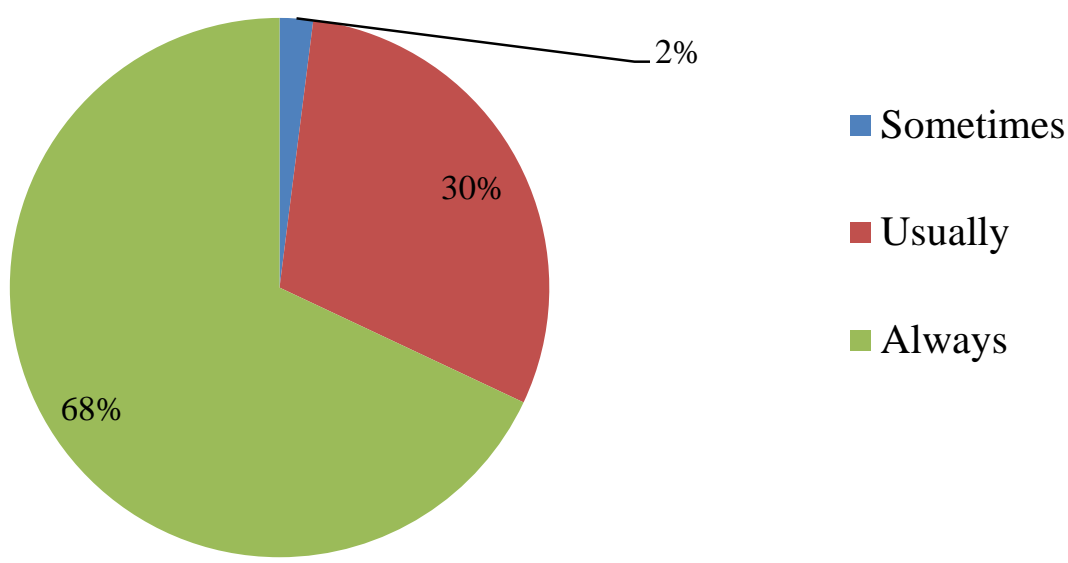

Figure 2: Frequency of students' dictionary consultation in translating ESP texts

A more profound insight into this matter can be found in Figure 3 and Figure 4, which indicated types of dictionaries (in terms of forms and languages) that the participants relied on for their ESP translation and their frequency level. Overall, it is clear from these figures that the majority of the students regularly employed at least two different types (in each category) when translating ESP texts.

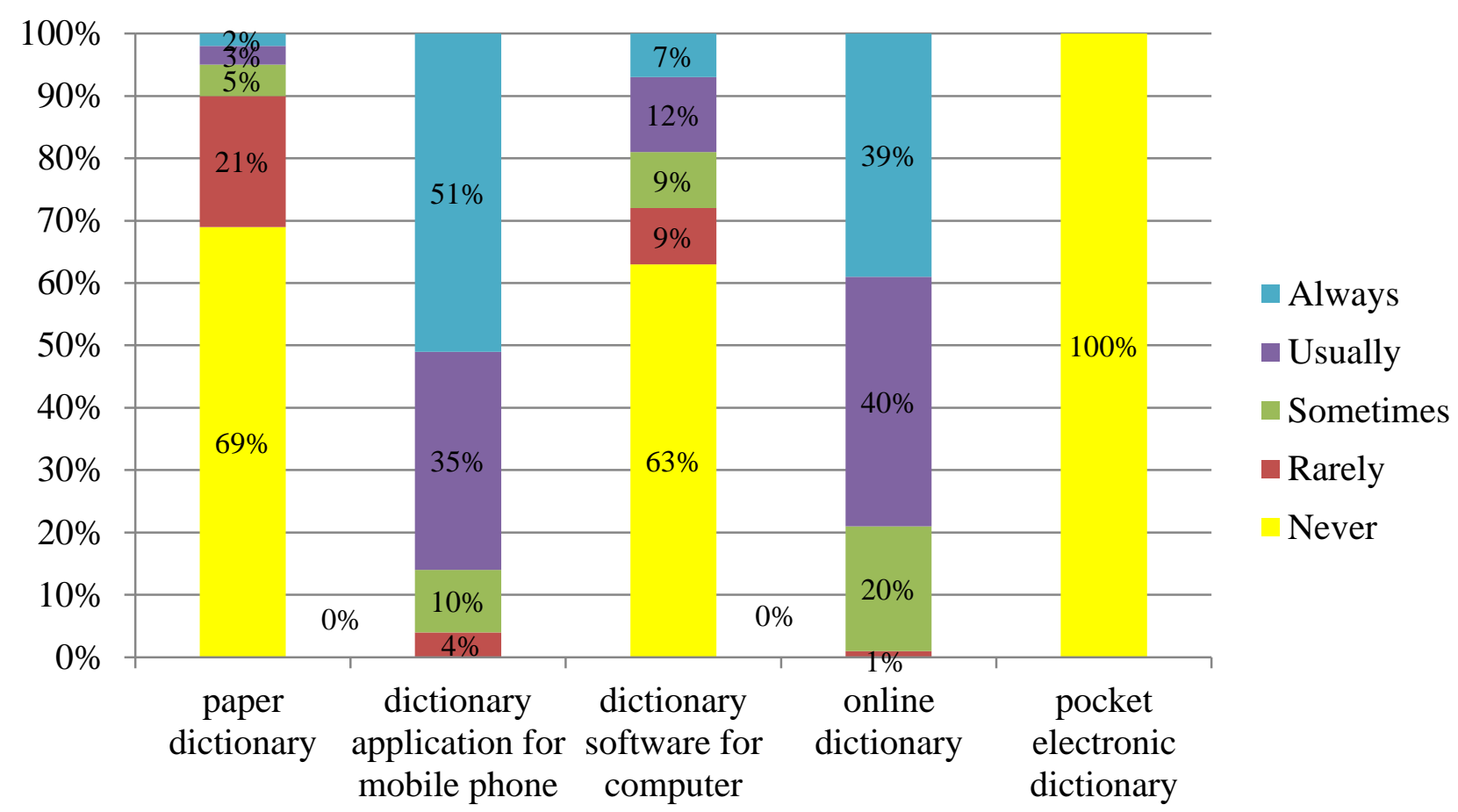

Figure 3: Types of dictionaries used by students in translating ESP texts (Form)

With regard to Figure 3, the most popular among the respondents was dictionary applications for mobile phones with roughly $85 \%$ of them usually or always consulting these 
while translating, closely followed by online dictionaries with approximately $80 \%$. Much less favored was dictionary software for computer with the number of users being nearly $30 \%$. Paper dictionaries were the least common with around $90 \%$ of the surveyed students never or rarely resorting to them. It is interesting to note that nobody chose a pocket electronic dictionary.

In addition, Figure 4 highlights the participants' marked preference for bilingual dictionaries in doing ESP translation tasks with more than $80 \%$ and roughly two thirds of them always or usually opting for English-Vietnamese dictionaries and Vietnamese-English ones respectively. Even though monolingual dictionaries were generally less favored as opposed to bilingual ones, the frequency level of using English-English dictionaries was still outstanding with around $70 \%$ of the respondents exploiting them. Not surprisingly, nearly $90 \%$ of the students asserted that Vietnamese-Vietnamese dictionaries were never or rarely their choice as being native speakers of the Vietnamese language appears to make them confident in understanding the Vietnamese source text.

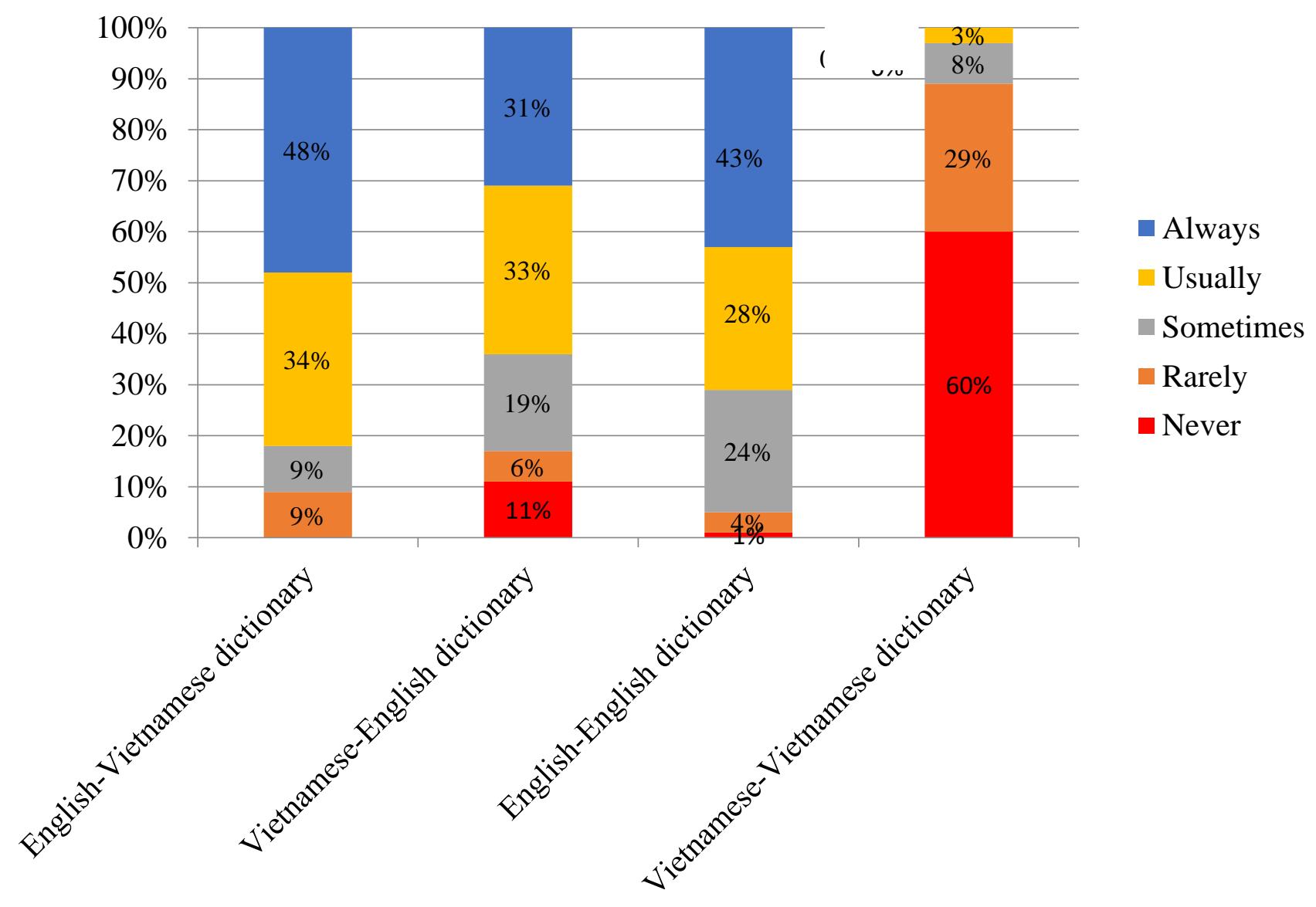

Figure 4: Types of dictionaries used by students in translating ESP texts (Language) 


\section{Lien Thi My Tong}

The findings were rather contradictory to those in Ahmad \& Haq (2010), who pointed out infrequent dictionary employment among a group of medical EFL students. This may be because the purpose of dictionary use among those medical students was merely for further information, which was totally different from that among the participants of the present study (i.e. for fulfilling translation tasks). Nonetheless, these findings were consistent with those in Fan (2000), Li (1998), and Małgorzata (2016) in that bilingual and online ones were the most popular among the students. As the populations of the abovementioned investigations and the current research were from various educational backgrounds, it could be inferred that these types might be so handy and useful that they would be favored in numerous contexts. Finally, unlike the subjects in Li's research (1998), who expressed strong preferences for pocket electronic dictionaries, none of those in this study resorted to this tool. This may be attributed to the fact that this tool was relatively expensive but not costeffective due to offering only a limited number of equivalents for each word without examples.

\subsection{Students' lookups when using dictionaries in translation practice in ESP courses}

Table 1: Students' lookups in dictionaries in translating ESP texts

\begin{tabular}{lccc}
\hline \multicolumn{1}{c}{ E-V/ V-E dictionaries } & Percentage & $\begin{array}{c}\text { E-E/ V-V } \\
\text { dictionaries }\end{array}$ & Percentage \\
\hline Equivalents & $76 \%$ & Word definitions & $77 \%$ \\
Grammar & $40 \%$ & Examples & $61 \%$ \\
Equivalent usage & $53 \%$ & Others & $13 \%$ \\
Examples & $56 \%$ & & \\
Others & $11 \%$ & & \\
\hline
\end{tabular}

Note: $E=$ English, $V=$ Vietnamese

A glance at Table 1 above indicates students' preferences in what they sought in different types of dictionaries in order to do their ESP translation tasks. It is necessary to mention that they were allowed to choose more than one lookup (in the questionnaire) for each type. In general, it is clear from the table that the respondents tended to search for more than one piece of information in each type of dictionaries, and they were likely to gain more support from bilingual dictionaries than monolingual ones since they sought for more information in the former than in the latter.

As for English-Vietnamese and Vietnamese-English ones, over three fourths of them claimed that this type of dictionaries provided them with equivalents while more than half searched for examples and equivalent usage, followed by grammar with approximately $40 \%$. The respondents also mentioned other information taken from bilingual dictionaries such as synonyms, antonyms, pronunciation, root words, and connotations. Noticeably, most of them 
looked for at least two different pieces of information to complete their translation. Meanwhile, monolingual dictionaries, namely English-English and Vietnamese-Vietnamese ones, were exploitable for word definitions by over three fourths of the participants, closely followed by examples with over 60\%. Other lookups were listed as follows: shade of meaning, word usage, collocation, word level, and grammar.

The aforementioned findings were similar to those by Haill \& Nesi (2002) and Liang $\& \mathrm{Xu}$ (2018) in that the students tended to look up definitions of new words and equivalents. Nonetheless, the current study ascertained a more massive amount of information that the participants sought in dictionaries. This may result from the fact that the subjects in Haill \& Nesi (2002) used dictionaries for the language acquisition purpose while this tool assisted the ones in Liang \& Xu (2018) in translating from another language instead of Vietnamese into English and vice versa. In other words, the purposes of dictionary use as well the source and target languages can determine sorts of students' lookups.

\subsection{Students' need for teachers' instructions in using dictionaries in translation practice in ESP courses}

It is clear from Figure 5 that approximately two thirds of the participants claimed that teachers' instructions in dictionary consultation in ESP courses were unnecessary while less than $30 \%$ expressed their demand for this assistance.

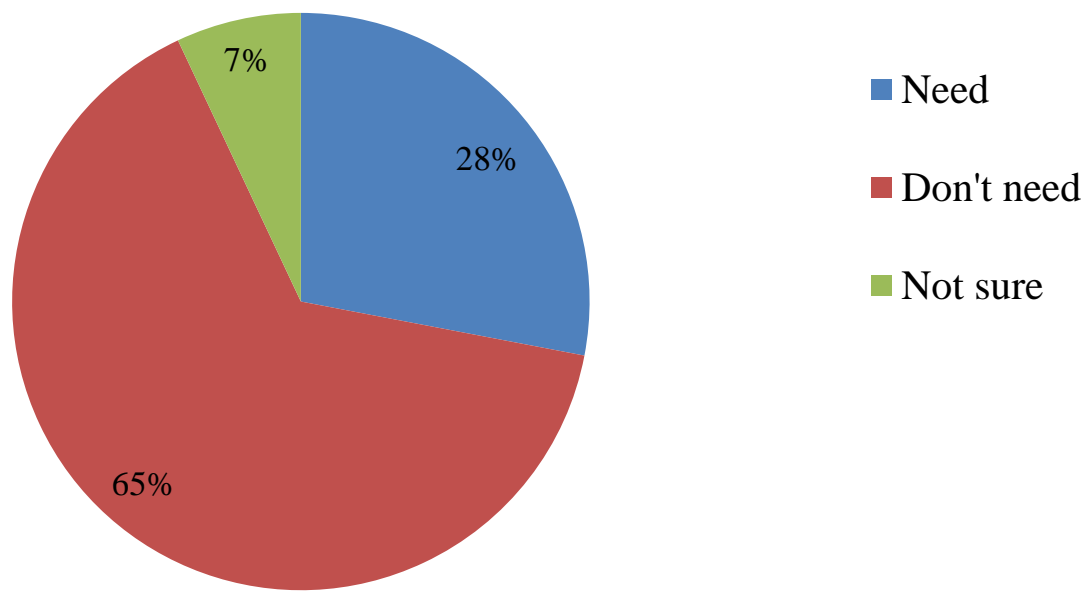

Figure 5: Students' need for teachers' instructions in using dictionaries in translating ESP texts

When asked to justify their reasons, three fourths of these $65 \%$ responded that they had already known how to use dictionaries in translating ESP texts as opposed to merely more than one fifth of these insisting on their ability to learn to employ dictionaries by themselves (see Figure 6). 
Lien Thi My Tong

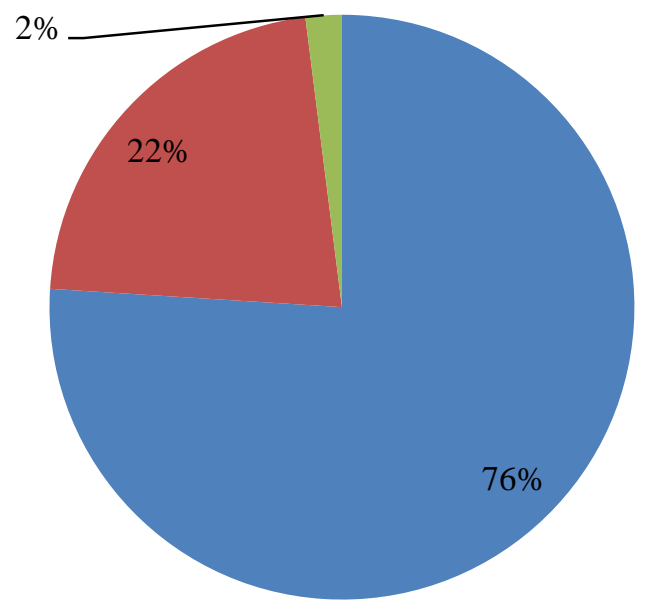

Already know how to use dictionaries in translation/ easy to use

Able to learn to use dictionaries by myself

Guided by others already

Figure 6: Reasons why students don't need teachers' instructions in using dictionaries in translating ESP texts

Targeting the respondents who desired teachers' instructions (21 students), Figure 7 illustrates that almost all of these expected to be guided to exploit a dictionary effectively while roughly half of them would like to know how to select a dictionary.

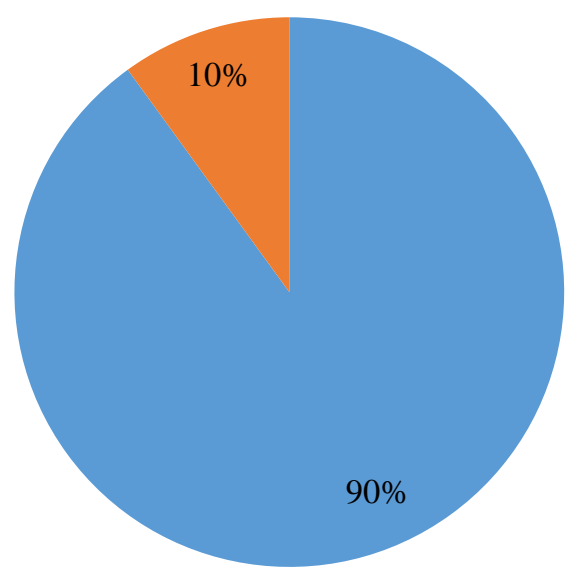

How to exploit a dictionary effectively

How to select a dictionary

Figure 7: Students' expectations of teachers' instructions in using dictionaries in translating ESP texts

Unlike the existing studies such as those by Li (1998), Ramos (2005), and Law (2009), which highlighted students' strong desire for teachers' guidance in dictionary consultation for translation tasks, the present investigation unveiled insignificant needs for that among the majority of students, which demonstrates their self-confidence in and familiarity with the employment of this tool. This might be again because of their majors involving plenty of English skills and subjects, leading to their wide experience of dictionary selection and utilization. 


\section{CONCLUSION}

The present study was an attempt to discover EFL students' habits of exploiting dictionaries in ESP translation in Vietnam's educational setting. First, it showed that the participants held positive attitudes towards the use of this tool and hence largely relied on it during the process of translating ESP texts. Second, it uncovered the immense popularity of dictionary applications for mobile phones and bilingual dictionaries among these learners. Third, it discovered a broad range of factors the students would consider for their choice of dictionaries, including the number of entries as the most significant. Fourth, it indicated that the learners tended to seek equivalents, examples, equivalent usage, and word definitions in dictionaries for the completion of ESP translation tasks. Finally, it revealed the students' confidence in exploiting the dictionaries effectively in translating ESP texts and their little desire for teachers' support and guidance. Based on the findings, it can be proposed that when teaching students translation practice in ESP courses, teachers should recommend reliable dictionaries, especially their favorite types, to them so that they can accomplish their translation tasks satisfactorily. Moreover, it is imperative that teachers guide students to employ both bilingual and monolingual dictionaries simultaneously to tackle a single translation problem. Further research might investigate the popularity of dictionaries in translation compared to other tools or the effectiveness of dictionary use in translation among EFL students.

\section{REFERENCES}

Abbott, B. B., \& Bordens, K. S. (1999). Research Design and Methods: A Process Approach (4th ed.). California: Mayfield Publishing Company.

Ahmad, A., \& Haq, H. M. (2010). Purpose of Dictionary Use in Professional Education: A Study of Dictionary Using Habits in Medical Students. Procedia - Social and Behavioral Sciences, 2, 3988-3993.

Avand, A. Q. (2009). Using Translation and Reading Comprehension of ESP Learners. The Asian ESP Journal, 5(1), 44-60.

Boonmoh, A. (2012). E-dictionary Use Under the Spotlight: Students' Use of Pocket Electronic Dictionaries for Writing. Lexikos, 22, 43-68.

Brown, J. D., \& Rodgers, T. S. (2002). Doing Second Language Research. Oxford: Oxford University Press.

Fan, M. Y. (2000). The Dictionary Look-up Behaviour of Hong Kong Students: A Largescale Survey. Education Journal, 28(1), 123-138.

Haill, R., \& Nesi, H. (2002). A study of Dictionary Use by International Students at a British University. International Journal of Lexicography, 15(4), 277-305.

Hartmann, R. R. K., \& James, G. (2000). Dictionary of Lexicography. Beijing: Foreign Language Teaching and Research Press.

Jin, L., \& Deifell, E. (2013). Foreign Language Learners' Use and Perception of Online Dictionaries. MERLOT Journal of Online Learning and Teaching, 9(4), 515-528.

Kondal, B. (2018). The Benefits of Using Dictionary Skills among the Third Year Pharmacy Students. International Journal of Management and Social Sciences Research, 7(11), $1-6$.

JELTL (Journal of English Language Teaching and Linguistics), 4(3), 2019 
Laufer, B., \& Hill, M. (2000). What Lexical Information Do L2 Learners Select in a CALL Dictionary and How Does It Affect Word Retention? Language Learning \& Technology, 3(2), 58-76.

Law, W. (2009). Translation Students' Use of Dictionaries: A Hong Kong Case Study for Chinese to English Translation. Retrieved January 12, 2019, from http://etheses.dur.ac.uk/729/

Li, L. (1998). Dictionaries and Their Users at Chinese Universities: With Special Reference to ESP Learners. Asia Conference. Hong Kong: Hong Kong University of Science and Technology.

Liang, P., \& Xu, D. (2018). An Empirical Study of EFL Learners' Dictionary Use in Chinese-English Translation. Lexikos, 28, 221-244.

Mahmoud, A. (2017). Should Dictionaries be Used in Translation Tests and Examinations? English Language Teaching, 10(3), 171-175.

Małgorzata, K. (2016). Dictionary-using Skills of Translation Students. The Central European Journal of Social Sciences and Humanities, 4, 235-242.

Mallick, G., \& Vajendra, K. V. (1999). Researching Education: Perspectives and Techniques. Oxford: Falmer Press.

Nunan, D. (1992). Research Methods in Language Learning. Cambridge: Cambridge University Press.

Ramos, M. M. S. (2005). Research on Dictionary Use by Trainee Translators. Translation Journal, 9(2).

Tananuraksakul, N. (2015). The Effect of Online Dictionaries Usage on EFL Undergraduate Students' Autonomy. Teaching English with Technology, 15(4), 3-15.

Zhang, R. (2010). Translation of Medical Research Paper Titles from Chinese into English Based on Corpus Linguistics. The Asian ESP Journal, 285-295.

Appendix: Survey questionnaire

\section{VIETNAMESE EFL STUDENTS’ HABITS OF USING DICTIONARIES IN TRANSLATION PRACTICE IN ESP COURSES}

All responses will be kept confidential and merely used for research purposes. Thank you for your contribution.

Note: Dictionaries include:

- Paper dictionaries

- Electronic dictionaries

- Dictionary applications for mobile phones

- Dictionary software for computers

- Online dictionaries

1. Do you think that using dictionaries in translation practice in ESP courses is beneficial?

Write $1 \rightarrow 5$

$(1=$ not beneficial at all $\rightarrow 5=$ extremely beneficial $)$

Answer:

2. How often do you use dictionaries in translation practice in ESP courses?

Write $1 \rightarrow 5$

$(1=$ Never $\rightarrow 5=$ Always $)$

Answer:

If your answer is 1 , please move to questions 3 and 4 . 
If you answer varies from 2 to 5 , please answer all the remaining questions (from question 5 to the last question).

3. Why do you never use dictionaries in translation practice in ESP courses?
A. Translation tasks are so easy that I do not have to look up anything.
B. Using dictionaries is time-consuming.
C. Information looked up in dictionaries is useless.
D. Other reasons (Please specify):

4. What other tools do you use instead of dictionaries?

A. Nothing

B. Google Translation

C. Search engines (i.e. yahoo.com, google.com)

D. Others (please specify):

5. What types of dictionaries do you use in translation practice in ESP courses? How often do you use them?

Write $1-5(1=$ Never $\rightarrow 5=$ Always $)$

\begin{tabular}{|c|c|c|c|}
\hline 5.1 Form & How often & 5.2 Language & How often \\
\hline A. Paper dictionary & & $\begin{array}{l}\text { A.English }- \text { Vietnamese } \\
\text { dictionary }\end{array}$ & \\
\hline $\begin{array}{l}\text { B. Dictionary application for } \\
\text { mobile phone }\end{array}$ & & $\begin{array}{l}\text { B.Vietnamese-English } \\
\text { dictionary }\end{array}$ & \\
\hline $\begin{array}{lll}\text { C. Dictionary software for } \\
\text { computer }\end{array}$ & & $\begin{array}{l}\text { C.English-English } \\
\text { dictionary }\end{array}$ & \\
\hline D. Online dictionary & & $\begin{array}{l}\text { D.Vietnamese-Vietnamese } \\
\text { dictionary }\end{array}$ & \\
\hline E. Electronic dictionary & & 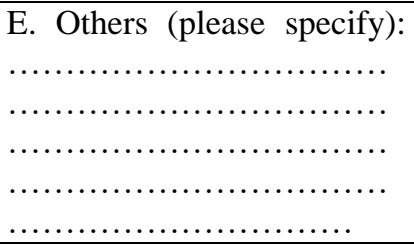 & \\
\hline
\end{tabular}

6. (Skip this question if you don't use English - Vietnamese dictionaries/ Vietnamese- English dictionaries) When using English - Vietnamese dictionaries/ Vietnamese- English dictionaries in translation practice in ESP courses, what do you look up? You can choose more than one choice.
A. Equivalents
B. Grammar
C. Equivalent usage
D. Examples
E. Others (please specify): 
7. (Skip this question if you don't use English - English dictionaries/ Vietnamese- Vietnamese dictionaries) When using English - English dictionaries/ Vietnamese- Vietnamese dictionaries in translation practice in ESP courses, what do you look up? You can choose more than one choice.

A. Word definitions

B. Examples

C. Please specify:

8. Do you need teachers' instructions on how to use dictionaries in translation practice in ESP courses?

A. Yes

B. No

C. Not sure

If you choose A, please move to question 9 .

If you choose $\mathrm{B}$ or $\mathrm{C}$, please move to question 10 .

9. If you choose A for question 8 , answer the following question: What instructions do you need? You can choose more than one choice.

A. How to select a dictionary

B. How to exploit a dictionary effectively

C. Others (please specify):

10. If you choose $\mathrm{B}$ or $\mathrm{C}$ for question 8, please specify your reasons.

\section{The end}

